\title{
PERSEPSI ALUMNI DAN STAKEHOLDER POLITEKNIK KESEHATAN SEMARANG TERHADAP KESESUAIAN KEMAMPUAN BAHASA INGGRIS SEBAGAI BEKAL MENGHADAPI KEBUTUHAN DUNIA KERJA
}

\author{
Salikun ${ }^{1}$, Supriyana ${ }^{2}$, Hermin Nugraheni ${ }^{3}$
}

\begin{abstract}
An English proviciency testl to to measure a person's level of competence in the field of English language should be appropriate to the needs of graduates in the workforce. Meanwhile Indonesia stigma most people still assume that the English language proficiency test is toefl, and less familiar with the other forms of test. In fact, every standardized test functions and has different characteristics. It became the basis of researchers to carry out a study of the English language proficiency test that is appropriate for vocational education as Kemenkes Polytechnic Semarang. For that study. The purpose of this study was to determine the suitability of English proficiency MoH Semarang Health Polytechnic students who have been certified using a test that has been applied in the current stakeholder needs.

This research is a descriptive study with a qualitative approach. Subjects in this study were polytechnic graduates Kemenkes Semarang and its stakeholders. Collecting data using two instruments, namely a questionnaire and interviews or in- depth interviews. Questionnaire data were analyzed using the criteria according heaton (1975:172). The data from in- depth interviews described in accordance with the subject 's perception of research.

The study results of this showed that the debriefing English language skills during the lectures can be said to be an improvement to be used when entering the workforce. Therefore debriefing skills required more intensive form of English proficiency for students of polytechnic Kemenkes Semarang. It is also necessary to reform the system of standardization the English language to fit the needs of alumni in the world of work.
\end{abstract}

Keywords : graduation, stakeholders, TOEIC, the world of work

$\overline{\text { 1,2,3) Dosen Jurusan Keperawatan Gigi Poltekkes Kemenkes Semarang }}$

\section{PENDAHULUAN}

\section{Kebutuhan akan kemampuan} berbahasa Inggris baik di dunia kerja maupun dunia akademik telah berkembang pesat. Berbagai perguruan tinggi di Indonesia pun berlomba-lomba untuk menghasilkan lulusan yang memiliki kemampuan berbahasa Inggris sebagai bekal menghadapi persaingan dunia kerja yang semakin ketat, termasuk Politeknik Kesehatan Kemenkes Semarang.

Berbagai usaha dilakukan, mulai dari mengintegrasikan Bahasa Inggris ke dalam kurikulum perkuliahan, memberikan fasilitas ekstrakurikuler di luar jam kuliah, penetapan standar minimum skor tes

Bahasa Inggris tertentu sebagai persyaratan yudisium maupun kelulusan, dan lain sebagainya. Dalam menentukan jenis dan skor tes yang akan dijadikan standar kelulusan pun harus melalui kajian yang mendalam untuk memahami unsur-unsur yang diujikan dalam tes tersebut. Hal ini dikarenakan penentuan standar itu harus disesuaikan dengan kebutuhan dan tujuan dibekalkannya standar tes tersebut kepada para lulusan. Hasil penelitian yang dilakukan Politeknik Kesehatan pada tahun 2010 melalui Risbinakes 2010 tentang "studi kesenjangan antara pembelajaran bahasa inggris pada mahasiswa politeknik kesehatan depkes semarang dengan kebutuhan komunikasi pelayanan kesehatan 
berbasis bahasa inggris pada rumah sakit internasional", menunjukkan bahwa adanya kesenjangan antara pembelajaran bahasa Inggris yang ada di Poltekes dengan kebutuhan di dunia kerja dimana di dunia kerja lebih tertumpu kepada penekanan akan conversation. TOEFL mendasari kompetensi Bhs Inggris yang dibutuhkan akan tetapi conversation lebih dibutuhkanTest of English for International Communication selanjutnya yang disingkat (TOEIC) adalah sebuah tes yang dapat digunakan untuk mengukur kemampuan berbahasa Inggris untuk individu yang sedang belajar atau bekerja di lingkungan internasional. Dengan demikian pemberian pembelajaran TOEIC lebih cocok untuk pendidikan vocational.

Di sisi lain, Politeknik kesehatan sebagai lembaga pendidikan vokasional yang mencetak kader-kader yang siap terjun ke dunia kerja tentu perlu untuk membekali mahasiswanya dengan keterampilan berbahasa Inggris untuk kepentingan dunia kerja. Untuk itu, standardized test yang digunakan untuk mengukur tingkat kemampuan mahasiswapun harus sesuai dengan tujuan tersebut.

Tujuan Penelitian ini untuk mengetahui kesesuaian kemampuan bahasa Inggris mahasiswa Politeknik Kesehatan Kemenkes Semarang yang telah disertifikasi menggunakan tes yang telah diterapkan saat ini di dengan kebutuhan stakeholder.

\section{Tinjauan Teoritis}

The test of English for International Communication (TOEIC) adalah tes profisiensi Bahasa Inggris yang didesain untuk mengukur kemampuan ketrampilan Bahasa Inggris seseorang yang bekerja dalam lingkungan internasional. Ada dua section tes dalam tes ini yaitu listening comprehension dan reading comprehension yang di bagi menjadi tujuh bagian yaitu : untuk listening comprehension bagian I : Picture, bagian II : Question-response, bagian III : Short Conversation, bagian IV : Short-talk, sedangkan untuk reading adalah bagian $\mathrm{V}$ : incomplete Sentences, bagian VI :
ErrorRecognition dan bagian VII : Reading Comprehension. Untuk dua section tersebut range scoreuntuk TOEIC adalah 10 sampai dengan 990. (LinLougheed, 2004 : xi ). Karena banyaknya jenis tes profisiensi Bahasa Inggris dengan tingkat skor yang berbeda, bahkan untuk TOEFL sendiri antara TOEFL Paper Based Test, Computer Based Test (TOEFL CBT) dan TOEFL internet Based Test (TOEFL IBT) mempunyai skor yang berbeda juga. Secara detail digambarkan perbandingan skor dan equivalennya berbagai tes profisiensi Bahasa Inggris dalam tabel berikut ini.

Pendidikan vokasi menganut sistem terbuka (multi-entry-exit system) dan multimakna (berorientasi pada pembudayaan, pemberdayaan, pembentukan watak, dan kepribadian, serta berbagai kecakapan hidup life skill. Pendidikan vokasi berorientasi pada kecakapan kerja sesuai dengan perkembangan ilmu pengetahuan dan teknologi terapan serta sesuai dengan tuntutan kebutuhan lapangan kerja. Pendidikan vokasi merupakan pendidikan keahlian terapan yang diselenggarakan di perguruan tinggi berbentuk akademi, politeknik, sekolah tinggi, institut dan universitas.

Kesiapan lulusan perguruan tinggi vokasi untuk terjun dan bersaing di dunia kerja menuntut mereka untuk memiliki bekal keterampilan yang akan memberikan nilai tambah bagi lulusan tersebut, termasuk ketrampilan berbahasa Inggris sebagai bahasa internasional yang diperlukan sebagai sarana komunkasi dunia kerja sehari-hari. Urgensi inipun juga mendorong politeknik-politeknik di Indonesia untuk membekali lulusannya dengan kemampuan Bahasa Inggris. Pembelajaran pun dilakukan se-efektif dan se-efisien mungkin mengingat jenjang waktu pendidikan yang berkisar antara 3-4 tahun. Di sinilah letak pentingnya menentukan strategi yang tepat untuk meningkatkan ketrampilan berbahasa Inggris tersebut, termasuk strategi pengukuran tingkat keberhasilannya melalui tes kecakapan berbahasa Inggris. 


\section{METODE PENELITIAN}

\section{a. Jenis dan Rancangan Penelitian}

Jenis penelitian yang digunakan metode kualitatif dengan kuisiner dan indept interview. Metode kualitatif digunakan dengan pertimbangan : pertama studi dalam situasi alamiah dalam arti peneliti tidak berusaha untuk memanipulasi setting penelitian melainkan melakukan studi terhadap suatu fenomena dimana fenomena tersebut ada. Kedua analisis induktif karena peneliti tidak memaksa diri untuk membatasi penelitian hanya pada upaya menerima atau menolak dugaan dugaan melainkan mencoba memahami situasi sesuai dengan bagaimana situasi tersebut menampilkan diri, ketiga kontak personel langsung disini peneliti berusaha mengembangkan hubungan personal langsung dengan yang diteliti, kempat perseptif holistik yaitu berusaha memahami secara menyuluruh terhadap masalah kendalamahasiswa tersebut. Dan kelima fleksibilitas desain dalam arti desain bisa berubah dilapangan. Keenam dari berbagai penelitian tentang kendala kendala berkomunikasi berbahasa Inggris telah dilakukan dengan menggunakan kuantitatif sehingga penelitian ini sifatnya memperkuat penelitian sebelumnya.

b. Subjek/sasaran Penelitian

Sasaran penelitian ini adalah alumni Poltekkes Kemenkes Semarang yang bekerja di rumah sakit International dan Stakeholder yang dalam hal ini adalah rumah sakit di tempat para alumni tersebut bekerja di lingkup Pulau Jawa.

\section{c. Teknik Pengumpulan data}

Pertama kami memberikan kuisiner baik kepada para alumni dan para stakeholder. Hal ini bertujuan untuk memberikan gambaran awal mengenai persepsi alumni dan stakeholder terhadap kesesuaian kemampuan Bahasa Inggris. Kedua, kami lakukan in-depth interview untuk mendapatkan informasi lebih dalam dan terperinci mengenai hal tersebut di atas. Panduan pertanyaan dalam in-depth interview memudahkan kami untuk menggali lebih jauh infrmasiinformasi yang kami dapatkan dari subjek penelitian karena sifat dari pertanyaannya yang terbuka dan fleksibel untuk dikembangkan.

\section{d. Instrumen Penelitian}

Instrumen dalam penelitian ini adalah berupa daftar pertanyaan, yang berisi panduan pertanyaan terbuka karena kami mengaplikasikan in-depth interview dalam penelitian ini. Selain itu peneliti juga menggunakan kuisioner untuk menjaring informasi-informasi yang terkait dengan penelitian ini.

\section{e. Teknik Analisis Data}

Setelah melalui prosedur pengumpulan data, selanjutnya kami mulai mengolah data-data yang kami dapatkan yaitu :

Pada tahapan ini kami mengolah datadata yang kami dapatkan selama pengumpulan data menggunakan kuisioner dan in-depth interview. Data yang kami peroleh dengan menggunakan kuisioner kami olah dengan skema penilaian sebagai berikut.

Pertama, kami mengklasifikasikan jawaban setiap pertanyaan dalam kuisioner.

Tabel 1 Klasifikasi kuisioner

\begin{tabular}{|c|c|}
\hline Jawaban & Skor \\
\hline Ya & 3 poin \\
\hline Ragu-ragu & 2 poin \\
\hline Tidak & 1 poin \\
\hline
\end{tabular}

Kedua, seluruh skor untuk tiap pertanyaan dijumlahkan. Ketiga, mencari skor rata-rata (mean) dari setiap pertanyaan dengan menggunakan rumus berikut:

Formula penentuan mean :

$$
\text { Mean }=\frac{\text { Total score }}{\text { The number of respondent }}
$$


Kemudian hasilnya kami klasifikasikan berdasarkan kriteria kuisioner yang dijelaskan oleh Heaton (1975:172).

Tabel 2 Kriteria kuisioner menurut Heaton

\begin{tabular}{|c|c|c|c|c|c|}
\hline $\begin{array}{c}\text { Range of } \\
\text { Mean }\end{array}$ & $\begin{array}{c}\text { Students' } \\
\text { Interest }\end{array}$ & $\begin{array}{c}\text { The } \\
\text { Advan- } \\
\text { tage }\end{array}$ & $\begin{array}{c}\text { Students' } \\
\text { Achieve- } \\
\text { ent }\end{array}$ & $\begin{array}{c}\text { The } \\
\text { Relevancy }\end{array}$ & $\begin{array}{c}\text { Sustain- } \\
\text { ability }\end{array}$ \\
\hline $0.00-1.00$ & Low & $\begin{array}{c}\text { Not } \\
\text { helpful }\end{array}$ & Low & $\begin{array}{c}\text { Not } \\
\text { relevant }\end{array}$ & $\begin{array}{c}\text { Not } \\
\text { necessary }\end{array}$ \\
\hline $1.01-2.00$ & Medium & Helpful & Medium & Relevant & Necessary \\
\hline $2.01-3.00$ & High & $\begin{array}{c}\text { Very } \\
\text { helpful }\end{array}$ & High & $\begin{array}{c}\text { Very } \\
\text { relevant }\end{array}$ & $\begin{array}{c}\text { Very } \\
\text { necessary }\end{array}$ \\
\hline
\end{tabular}

\section{Metode analisis hasil in-depth interview}

Dalam in-depth interview ini kami menggunakan jenis semi-structured interview di mana peneliti hanya menyiapkan beberapa pertanyaan panduan (guide questions) yang bersifat terbuka. Pertanyaan panduan ini bersifat fleksibel sehingga dapat dikembangkan menjadi pertanyaan-pertanyaan lain yang lebih rinci sesuai dengan kondisi dan situasi selam wawancara berlangsung. Hasil dari wawancara ini tentunya dapat memperkaya informasi yang kami butuhkan yang tidak bisa diperoleh lewat kuisioner. Selanjutnya hasil wawancara akan dideskripsikan sesuai dengan persepsi subjek penelitian

\section{HASIL DAN PEMBAHASAN}

Pengambilan data dilaksanakan dalam 2 kelompok. Kelompok pertama adalah para alumni, sedangkan kelompok ke dua adalah kelompok stakeholder. Sedangkan tahapannya dibagi ke dalam dua tahapan. Tahapan pertama adalah pengumpulan data dengan kuisiner, dan yang kedua adalah indepth interview.

\section{Analisa Kuisiner}

Tujuan didistribusikannya kuisiner adalah untuk mendapatkan gambaran awal secara umum mengenai persepsi alumni dan stakeholder terhadap kesesuaian kemampuan berbahasa Inggris. Tabel berikut adalah penjelasan mengenai hasil yang kami terima dari analisa kuisioner dalam penelitian ini adalah sebagai berikut.

Tabel 3. Analisa hasil kuisioner

\begin{tabular}{|c|c|c|c|c|}
\hline $\mathrm{NO}$ & PERTANYAAN & $\begin{array}{c}\text { MEAN } \\
\text { PERTANYAAN }\end{array}$ & KATEGORI & INTERPRETASI \\
\hline 1. & $\begin{array}{lr}\text { Apakah } & \text { menurut } \\
\text { mahasiswa } & \text { politeknik } \\
\text { Kesehatan } & \text { perlu memiliki } \\
\text { standar } & \text { kemampuan } \\
\text { berbahasa } & \text { Inggris? }\end{array}$ & 2.2 & high & \begin{tabular}{lr} 
Mahasiswa & \multicolumn{2}{r}{ politeknik } \\
Kesehatan & sangat perlu \\
memiliki & standar \\
kemampuan & berbahasa \\
Inggris & \\
\end{tabular} \\
\hline 2. & $\begin{array}{l}\text { Apakah anda setuju } \\
\text { kemampuan bahasa Inggris } \\
\text { yang harus dimiliki oleh } \\
\text { lulusan adalah kemampuan } \\
\text { berkomunikasi dengan klien } \\
\text { (pasien, dokter dan teman } \\
\text { sejawat)? }\end{array}$ & 2.1 & high & $\begin{array}{l}\text { kemampuan bahasa } \\
\text { Inggris yang harus } \\
\text { dimiliki oleh lulusan } \\
\text { adalah kemampuan } \\
\text { berkomunikasi dengan } \\
\text { klien }\end{array}$ \\
\hline 3. & $\begin{array}{l}\text { Bila tidak setuju pada nomor } \\
\text { soal kemudian } \\
\text { kemampuan bahasa Inggris } \\
\text { yang harus dimiliki oleh } \\
\text { lulusan adalah kemampuan } \\
\text { bisa membaca literature } \\
\text { (petunjuk dalm label obat, } \\
\text { kartu status, SOP dll)? }\end{array}$ & 1.9 & medium & $\begin{array}{l}\text { sebagian dari alumni } \\
\text { setuju dengan pertanyaan } \\
\text { di atas }\end{array}$ \\
\hline 4. & $\begin{array}{l}\text { Apakah menurut anda } \\
\text { mahasiswa politeknik } \\
\text { Kesehatan perlu mengikuti } \\
\text { tes kemampuan berbahasa } \\
\text { Inggris? }\end{array}$ & 2.3 & high & $\begin{array}{l}\text { tes kemampuan bahasa } \\
\text { inggris sangat diperlukan } \\
\text { bagi mahasiswa politeknik } \\
\text { kesehatan. }\end{array}$ \\
\hline
\end{tabular}




\begin{tabular}{|c|c|c|c|c|}
\hline 5. & 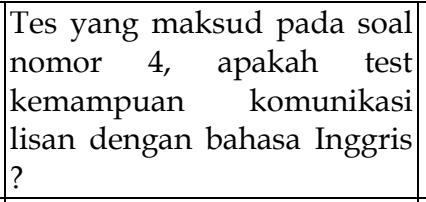 & 2.0 & medium & \begin{tabular}{|lr} 
bahwa ada & beberapa \\
respnden & yang \\
beranggapan seperti & pada \\
pertanyaan di atas. &
\end{tabular} \\
\hline 6. & \begin{tabular}{|l} 
Masih terkait dengan soal no \\
4, ataukah test kemampuan \\
akademik (memahami \\
grammar) \\
bahasa Inggris?
\end{tabular} & 1.8 & medium & $\begin{array}{l}\text { ada beberapa responden } \\
\text { yang beranggapan seperti } \\
\text { pada pertanyaan di atas. }\end{array}$ \\
\hline 7. & $\begin{array}{l}\text { Apakah anda tahu apa itu } \\
\text { TOEIC@ Test of English for } \\
\text { International } \\
\text { Communication? }\end{array}$ & 1.9 & medium & $\begin{array}{l}\text { bahwabeberapa responden } \\
\text { mengenal jenis tes TOEIC }(\end{array}$ \\
\hline 8. & $\begin{array}{l}\text { Apa penggunaan dari tes } \\
\text { TOEIC } \AA \text { untuk mengukur } \\
\text { kemampuan bahasa Inggris } \\
\text { cara membaca literature? }\end{array}$ & 1.3 & medium & $\begin{array}{|lr|}\text { sebagian } & \text { responden } \\
\text { membenarkan } & \text { pertanyaan } \\
\text { tersebut. } & \\
\end{array}$ \\
\hline 9. & \begin{tabular}{|lr} 
Jika & mengenal apakah anda \\
menyukai & TOEIC $~$ \\
dibandingkan & dengan jenis \\
tes lain? &
\end{tabular} & 2.1 & high & $\begin{array}{l}\text { sebagian besar responden } \\
\text { menyukai jenis tes ini. }\end{array}$ \\
\hline 10. & 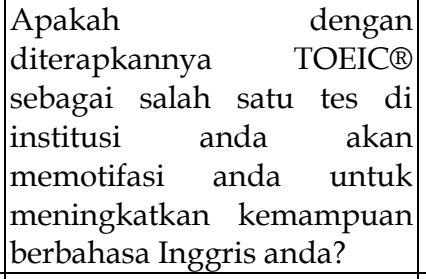 & 2.3 & high & \begin{tabular}{|l|} 
penerapan TOEIC $\AA$ sangat \\
berguna untuk memotifasi \\
mereka untuk \\
meningkatkan \\
kemampuan berbahasa \\
Inggris mereka.
\end{tabular} \\
\hline 11. & $\begin{array}{l}\text { Apakah skor TOEIC® lebih } \\
\text { menggambarkan } \\
\text { kemampuan Bahasa Inggris } \\
\text { anda daripada jenis tes lain? }\end{array}$ & 2.2 & high & $\begin{array}{l}\text { skor TOEIC® lebih } \\
\text { menggambarkan } \\
\text { kemampuan Bahasa } \\
\text { Inggris mereka daripada } \\
\text { jenis tes lain. }\end{array}$ \\
\hline 12. & $\begin{array}{|lcr|}\text { Apakah } & \text { menurut } & \text { anda } \\
\text { TOEIC® } & \text { sesuai } & \text { diterapkan } \\
\text { sebagai } & \text { tes } & \text { kecakapan } \\
\text { Bahasa Inggris di } & \text { politeknik } \\
\text { kesehatan? }\end{array}$ & 2.2 & high & $\begin{array}{|lrr|}\text { menurut } & \text { responden } \\
\text { TOEIC® } & \text { sesuai } & \text { diterapkan } \\
\text { sebagai } & \text { tes } & \text { kecakapan } \\
\text { Bahasa } & \text { Inggris di } \\
\text { politeknik } & \text { kesehatan. }\end{array}$ \\
\hline 13. & $\begin{array}{l}\text { Apakah menurut anda jika } \\
\text { TOEIC® diterapkan sebagai } \\
\text { salah satu tes di institusi } \\
\text { anda program tersebut perlu } \\
\text { dilanjutkan? }\end{array}$ & 2.3 & high & $\begin{array}{|lr|}\text { responden } & \text { berasumsi } \\
\text { bahwa } & \text { penerapan } \\
\text { TOEIC®perlu dilanjutkan }\end{array}$ \\
\hline
\end{tabular}

\section{Analisa in-depth interview}

Tahap selanjutnya adalah menganalisa data yang diperoleh dari in-depth interview. Pertanyaan pertama adalah mengenai perlu tidaknya mahasiswa politeknik kesehatan memiliki standar kemampuan berbahasa inggris. Responden yang dipilih dari kelompok alumni menjawab "perlu". Menurut mereka, Bahasa Inggris telah menjadi sebuah tuntutan yang umum berlaku di dunia kerja, jadi mahasiswa sebaiknya memiliki estándar kemampuan yang bisa dijadikan modal menghadapi dunia kerja. Sedangakan responden dari kelompok stakehlder juga memberikan jawaban serupa bahwa tidak hanya skill utama yang diperlukan dalam bekerja, skillskill penunjang seperti kemampuan berbahasa Inggris juga sangat penting untuk dikuasai.

Pertanyaan kedua adalah mengenai jenis kemampuan berbahasa inggris yang bagaimana yang diinginkan oleh pengguna lulusan. Kelompok stakeholder mengutarakan bahwa kemampuan yang 
diperlukan tidak hanya sebatas bisa memahami bahasa tertulis, tetapi juga dapat berkmunikasi secara lisan dengan baik. Sedangkan kelompok alumni juga berpendapat senada dengan kelompok stakeholder.

Pertanyaan ketiga adalah cukup atau kurangnya pembelajaran bahasa Inggris selama di perguruan tinggi. Dari sudut pandang alumni dapat disimpulkan bahwa pembelajaran bahasa Inggris selama di perguruan tinggi dirasa kurang. Selama menempuh pendidikan di perguruan tinggi mereka harus mencari tambahan bimbingan bahasa Inggris di luar kelas atau kampus. Sedangkan dari sudut pandang stakeholder sebagai pihak yang mempekerjakan para alumni beranggapan bahwa memang pembelajaran di perguruan tinggi masih kurang. Satu hal yang menarik adalah seorang responden menceritakan bahwa permasalahan yang sering dijumpai adalah alumni kurang bisa berkomunikasi dalam bahasa Inggris padahal nilai yang ia peroleh selama kuliah sangat tinggi.

Pertanyaan keempat adalah apakah sistem penilaian kemampuan bahasa Inggris yang saat ini diterapkan cukup menggambarkan kemampuan berbahasa Inggris seseorang yang sebenarnya? Kelompok alumni tidak terlalu yakin dalam menjawab pertanyaan ini. Ada beberapa alumni yang mengatakan bahwa meskipun skor TOEFL mereka cukup tinggi, mereka masih mengalami kesulitan jika harus berkomunikasi di tempat kerja. Di satu sisi kelompok stakeholder mengutarakan hal yang hampir sama.

Pertanyaan kelima adalah mengenai jenis-jenis standardized test yang diketahui oleh para responden. Dari informasi yang kami peroleh bahwa selain TOEFL, responden juga mengenal jenis-jenis tes lain seperti IELTS, TOEIC, GMAT, dsb. Ketika diminta untuk membandingkan standardized tes mana yang hampir mendekati kebutuhan di dunia kerja dilihat dari segi kegunaan, gaya bahasa yang digunakan, dan segi pemaparan hasil tes, kelompok alumni menjawab bahwa TOIEC lah yang lebih mendekati. Stakeholder juga memiliki pandangan yang serupa. Mereka membandingkan antara alumni yang memiliki sertifikat TOEIC dengan skor yang baik biasanya lebih mampu dalam berkomunikasi di dunia kerja daripada alumni yang hanya memiliki sertifikat TOEFL.

Dari hasil yang diperoleh dari pendistribusian kuisioner dan in-depth interview didapatkan informasi bahwa:

1. Untuk menghadapi persaingan dunia kerja diperlukan pembekalan skill berupa kecakapan berbahasa Inggris. Kecakapan yang dimaksud tidak hanya berupa kecakapan dalam memahami bahasa tertulis seperti memahami manual alat medis, memahami instruksi dalam label obat, dan lain sebagainya. Namun juga perlu untuk terampil dalam berkomunikasi dalam bahasa Inggris secara lisan, hal ini terlihat bahwa responden setuju bahwa penggunaan preparation dan tes TOEIC sangat penting

2. Pembekalan skill bahasa Inggris selama di perguruan tinggi dirasa kurang. Hal ini mengindikasikan bahwa baik dari segi porsi waktu, metode pembelajaran, dan kurikulum di perguruan tinggi khususnya politeknik kesehatan perlu ditingkatkan.

3. Perlu adanya pembenahan terhadap sistem standarisasi kemampun berbahasa Inggris karena menurut informasi yang diperoleh dari kedua tahap pengumpulan data tersebut terjadi kesenjangan antara skor tinggi dalam TOEFL dengan kemampuan seorang alumni dalam berkomunikasi dalam bahasa Inggris. Hal ini dikarenakan TOEFL bukanlah tolok ukur yang sesuai untuk mahasiswa sekolah vokasiaonal yang notabene dipersiapkan untuk langsung terjun ke dunia kerja. Dari segi fungsi, pemilihan bahasa, dan bentuk deskripsi hasil, sejauh ini TOEIC sebagai salah satu standardized test yang paling mendekati kebutuhan lulusan sekolah vokasi. Selain itu tes ini juga 
memudahkan stakeholder dalam memahami makna skor serta skill yang dikuasai dengan jumlah skor yang tertera dalam sertifikat tersebut. Maka dari itu, alangkah baiknya bahwa penerapan tes TOEIC sebagai tes sertifikasi Bahasa Inggris mahasiswa Poltekkes Kemenkes Semarang dipertimbangkan.

\section{KESIMPULAN}

Kesimpulan yang dapat kita ambil dari penelitian ini adalah:

1. Pembekalan skill Bahasa Inggris selama perkuliahan dapat dikatakan kurang memberikan peningkatan untuk dipergunakan ketika memasuki dunia kerja.

2. Diperlukan pembekalan skill yang lebih intensif berupa kecakapan berbahasa Inggris bagi mahasiswa Poltekkes Kemenkes Semarang.

3. Perlu adanya pembenahan terhadap sistem standarisasi kemampun berbahasa Inggris agar sesuai dengan kebutuhan alumni di dunia kerja.

\section{SARAN}

Bagi Poltekkes Kemenkes Semarang sebagai salah satu institusi perguruan tinggi yang terus berupaya meningkatkan kualitas skill lulusannya juga hendaknya perlu untuk kembali mengkaji mengenai penerapan alat ukur kecakapan berbahasa Inggris yang sesuai untuk pendidikan vokasional seperti Poltekkes Kemenkes Semarang.

\section{DAFTAR PUSTAKA}

Burns., N., and Grove., S. K. (1977). The Practice of Nursing Research (3rd ed.). Philadelphia: Saunders

Educational Testing Service (2009). TOEIC® Newsletter.
Educational Testing Service (2010). Executive Summary Perkembangan Tes Bahasa Inggris TOEFL ${ }^{\circledR}$ dan TOEIC®.

Educational Testing Service (2013). TOEIC® Information Book.

Lin Lougheed, Longman Preparation Series for the TOEIC Test, Pearson Education Inc, White Plains, 2005.

Megayanti, R. (2010). Documentary Photographs as Media in Developing Students' Ability in Writing Analytical Exposition Text. An Action Research to the Eleventh Graders of SMA N I Grobogan in the Academic Year 2009/2010. Unpublished S1 Final Project. The State University of Semarang. Semarang.

Polit., D.F. and Hungler., B.P. (1999). Nursing Research, Principles, and Method, 6th. Ed. Lippincott. Philadelpia-New York-Baltimore.

Raharjo, S. (2010).Mencari Bentuk Standardisasi Kemampuan Berbahasa Inggris yang Tepat bagi Mahasiswa Politeknik Negeri Semarang.

Suminto (2010). TOEFL, IELTS atau TOEIC Instrumen yang Tepat Untuk Mengukur Kemampuan Bahasa Inggris Mahasiswa Politeknik Negeri Samarinda.

Website: http: // www.teachingenglish.org.uk /accessed 1/04/2013 http://www.ugm.ac.id/accessed $2 / 04 / 2013$ 